\title{
Production of functional non-dairy creamer using Nigella sativa oil via fluidized bed coating technology
}

\begin{abstract}
Nigella sativa oil has a high potential to be developed into bioactive food ingredients. The aim of this study is to produce a lowfat, non-dairy creamer (NDC) from Nigella sativa oil (NSO) that is extracted by a supercritical fluid technique. The emulsion was processed with total solids of $40 \%$ and the drying process was performed using a spray dry technique at $160{ }^{\circ} \mathrm{C}$ inlet air temperature to obtain the microencapsulated oil. The agglomeration conditions (fluidizing time, fluid air temperature, and feed flow rate), were optimized using a response surface methodology (RSM) with a central composite design. The microencapsulated oil demonstrated low moisture content, high water solubility, strong antioxidant activity and high thymoquinone content in the developed creamer. The optimum conditions of the fluidized bed drying process were inlet air temperature $\left(50{ }^{\circ} \mathrm{C}\right)$, drying time $(25 \mathrm{~min})$, and feed flow rate $(1 \mathrm{~mL} / \mathrm{min})$. The sensory evaluation revealed that consumers' acceptability is high for the developed coffee creamer. The findings indicated the high potential of the microencapsulated oil for applications to mass produce and commercialize functional non-dairy creamer.
\end{abstract}

Keyword: Functional beverages; Agglomeration; Fluidized bed-drying; Antioxidant; Nigella sativa oil 